\title{
Influence of Treatment Modalities on Body Weight in Acute Lymphoblastic Leukemia
}

\author{
J.J. Groot-Loonen, $\mathrm{MD}, \mathrm{B} . J$. Otten, $\mathrm{MD}$, $\mathrm{PhD}$, \\ M.A. van't Hof, PhD, R.J.J. Lippens, MD, PhD, and G.B.A. Stoelinga, MD, PhD
}

Weight for height of 92 patients ( 51 girls and 41 boys) treated for acute lymphoblastic leukemia (ALL) was evaiuated in a longitudinal study. Fifty-four patients received cranial irradiation (CI) with a dose of 18 or 24 Gy and 38 patients did not receive $\mathrm{Cl}$. Seventy-seven patients were treated according to a normal-risk protocol and 75 patients received more intensive chemotherapy according to a high-risk protocol. In most of the patients the duration of follow-up was 12 years for irradiated patients and 4.5 years for the nonirradiated patients.

Thirty of 92 patients were treated according to a protocol without $\mathrm{Cl}$, but with a difference in the use of corticosteroids: 19 patients received dexamethasone during the remission-induction and maintenance treatment and 11 patients received prednisone. The influence of dexametha- sone vs. prednisone, sex, $\mathrm{Cl}$ and high-dose vs.low-dose chemotherapy on weight for height was evaluated. Patients who received dexamethasone showed a significant increase in weight for height immediately after the start of therapy. In patients who received $\mathrm{Cl}$, weight for height significantly increased after the first year of treatment. The overweight in these patients persisted during the whole follow-up period. The weight for height of patients treated with prednisone and of patients who did not receive Cl was below the mean of the normal population during treatment but was not different from normal after cessation of therapy. No difference in weight gain was seen between boys and girls and between patients who were treated with high vs. normal-risk protocols. (c) 1996 Wiley-Liss, Inc.

Key words: ALL, cranial irradiation, weight for height

\section{INTRODUCTION}

During the last decade many studies have been published on linear growth of children treated for acute lymphoblastic leukemia (ALL), concluding that retardation of linear growth during treatment is a common observation [1-7]. Data about weight gain in these patients are limited. Malnutrition leading to loss of weight, as a consequence of the disease itself or the side effects of chemotherapy, might be one of the causal factors of early growth deceleration. Our clinical impression, however, is that several patients showed excessive weight gain during and after treatment. Other authors also noticed obesity in a number of children during and after treatment for ALL [8-13], but it is not clear if all the treatment modalities are associated with a higher risk for developing obesity.

In this study we evaluated weight development during and after treatment for ALL in order to answer the following questions:

1. Does the Z-score of weight for height decline during the period of treatment of children treated for ALL?

2. Is the pattern of body weight development influenced by treatment?

(c) 1996 Wiley-Liss, Inc.
3. Could we identify treatment factors related to the pattern of weight development in these patients?

\section{PATIENTS AND METHODS}

\section{Patients}

Ninety-two consecutive patients with ALL treated at the Department of Paediatric Oncology of the University Hospital Nijmegen between 1972 and 1988 were included in the study. Data about age and sex are shown in Table I. Since central nervous system (CNS) involvement could cause hypothalamic dysfunction [14], patients with CNS involvement were excluded from the study. All patients had entered into first remission within 6 weeks after diagnosis. Patients with relapse of their disease were excluded from the study.

From the Departments of Pediatric Oncology (J.J.G.-L., R.J.J.L.), Pediatric Endocrinology (B.J.O., G.B.A.S.), and Medical Mathematics (M.A.v.H.), University of Nijmegen, Nijmegen, The Netherlands.

Received May 31, 1994; accepted October 3, 1995.

J.J. Groot-Loonen, M.D., Department of Pediatric Oncology, University of Nijmegen, P.O. Box 9101, 6500 HB Nijmegen, The Netherlands. 
TABLE I. Mean Ages at Diagnosis, the Range of the Ages, and the Sexes of the Patients in Different Treatment Groups

\begin{tabular}{|c|c|c|c|c|c|c|}
\hline & \multirow{2}{*}{$\begin{array}{l}\text { High-risk } \\
(\mathrm{n}=15)\end{array}$} & \multirow{2}{*}{$\begin{array}{c}\text { Normal-risk } \\
(\mathrm{n}=77)\end{array}$} & \multicolumn{2}{|c|}{ Protocol 6} & \multirow[b]{2}{*}{$\mathrm{Cl}(\mathrm{n}=54)$} & \multirow[b]{2}{*}{ Non-CI $(\mathrm{n}=38)$} \\
\hline & & & $\operatorname{Dexa}(n=19)$ & Pred $(n=11)$ & & \\
\hline o & 6 & 35 & 11 & 7 & 21 & 20 \\
\hline$q$ & 9 & 42 & 8 & 4 & 33 & 18 \\
\hline Mean age (years) & 6.7 & 5.2 & 5.5 & 5.5 & 5.5 & 5.5 \\
\hline Range & $1.1-15.9$ & $0.6-15.5$ & $2.3-12.3$ & $1.6-13.9$ & $0.6-15.9$ & $1.1-14.4$ \\
\hline
\end{tabular}

\section{Treatment}

Depending on the risk factor of leukemia, patients were divided into two groups. Group I included 77 patients with normal-risk leukemia, i.e., they had a leukocyte count in the peripheral blood $<50,000 / \mathrm{mm}^{3}$, without mediastinal enlargement. This group was treated according to the consecutive protocols 2, 3,5, and 6 of the Dutch Leukemia Working Group. Protocols 2, 3, and 5 comprised induction treatment with vincristine (VCR), prednisone (Pred), with or without L-asparaginase (L-Asp), and maintenance treatment with 6-mercaptopurine (6-MP), methotrexate (MTX) alternated with VCR and Pred.

Thirty patients were treated according to protocol 6 , 19 of whom (group Ia) received induction treatment with VCR, dexamethasone (Dexa) $6 \mathrm{mg} / \mathrm{m}^{2}$, and L-Asp and maintenance treatment with 6-MP, MTX alternated with VCR, Dexa. Eleven patients (group Ib) received the same treatment with only a difference in the corticosteroid medication. In these patients Dexa was replaced by Pred 40 $\mathrm{mg} / \mathrm{m}^{2}$, a dose nearly equal on the basis of glucocorticoid activity.

Group II included 15 patients with high-risk leukemia, i.e., they had a leukocyte count $>50,000 / \mathrm{mm}^{3}$ and/or mediastinal enlargement. They were treated according to a high-risk protocol comprising induction treatment with cyclophosphamide (Cyclo), VCR, Pred, L-Asp, and Adriamycin (Adria). The maintenance treatment consisted of 6-MP, MTX, and Cyclo alternated with VCR, Pred, Adria, and cytosine-arabinoside (Ara-C).

Depending on the method of CNS prophylaxis, patients were divided in two groups. Group A, which included 54 patients treated between 1972 and 1984, received cranial irradiation (CI). Thirty-seven patients received a dose of $24 \mathrm{~Gy}$ in 13 fractions over 17 days and five doses of MTX and Pred intrathecally (i.t.) and 17 patients received $18 \mathrm{~Gy} \mathrm{CI}$ in 10 fractions over 14 days and five doses of MTX and Pred i.t. (1972-1984). None of the patients received spinal irradiation. The timing of the CI was 5-6 weeks after diagnosis for all patients. Duration of followup was up to 12 years.

Group B, which included 38 patients treated between 1984 and 1988, did not receive CI. The CNS prophylaxis in these patients consisted of high-dose MTX intravenously combined with MTX and Pred i.t. During mainte- nance treatment, eight doses of MTX, Pred, and Ara-C were given i.t. Duration of follow-up was up to 4.5 years.

Forty-three of 77 patients with normal-risk and 11 of 15 patients with high-risk leukemia received CI. The number of patients during the follow-up period is shown in Table II.

\section{Measurements and Methods}

Patients' heights and weights were measured by experienced staff. During the 2 years of treatment, patients were measured 8-12 times per year and during the years of follow-up one to four times per year. Weight for height was studied. In order to compare the patients' groups with the general population, Z-scores were calculated for weight for height using Dutch reference values [15]. The Z-score is defined as the difference between a patients' weight and the stature and sex appropriate mean divided by the corresponding standard deviation. Weight for height is known to be positively skewed distributed, therefore, a log-transformation after translation $\ln (x-c)$ was applied comparable to the method developed by van ' $t$ Hof et al. [16]. The translation (c) is stature and sex dependent. The translation was chosen so that a symmetric distribution with regard to the $P_{10}, P_{50}$, and $P_{90}$ was obtained. The transformed distribution was used for the calculation of the Z-scores. Estimates of the Z-scores at regular time intervals were obtained by interpolation in the individual Z-score curves.

\section{Statistical Analysis}

Statistical comparisons were made using Student's t-test and analysis of variance (ANOVA). Significance was accepted for $P<0.05$.

\section{RESULTS}

In order to investigate the influence of different glucocorticoids on body weight development, we compared the Z-scores of weight for height of patients treated according to protocol 6 of the Dutch Leukemia Working Group with Dexa (group Ia) with the Z-scores of patients who received Pred instead of Dexa (group Ib) (Fig. 1). The chemotherapy in both groups was the same and neither of these patients received CI. At diagnosis, the Z-score of 
TABLE II. Number of Patients During Follow-Up $(\mathbf{n}=\mathbf{9 2})^{*}$

\begin{tabular}{|c|c|c|c|c|c|c|c|c|c|c|c|c|c|c|c|}
\hline $\begin{array}{l}\text { Duration in follow-up } \\
\text { (years) }\end{array}$ & 0 & 0.25 & 1 & 2 & 3 & 4 & 4.5 & 5 & 6 & 7 & 8 & 9 & 10 & 11 & 12 \\
\hline $\mathrm{CI}($ group A) & 45 & 54 & 54 & 54 & 54 & 53 & 52 & 51 & 47 & 45 & 42 & 41 & 33 & 26 & 19 \\
\hline $\begin{array}{l}\text { No irradiation, exclusive } \\
\text { Dexa patients (group B) }\end{array}$ & 15 & 19 & 19 & 19 & 14 & 13 & 11 & & & & & & & & \\
\hline \multicolumn{16}{|l|}{ No irradiation } \\
\hline Protocol 6: Dexa (group Ia) & 14 & 19 & 19 & 19 & 18 & 13 & 7 & & & & & & & & \\
\hline Protocol 6: Pred (group Ib) & 8 & 11 & 11 & 11 & 6 & 6 & 5 & & & & & & & & \\
\hline Other protocol & 7 & 8 & 8 & 8 & 8 & 7 & 6 & & & & & & & & \\
\hline
\end{tabular}

*A number of the initial values were missing. At 3 months after diagnosis all patients had entered the averages.

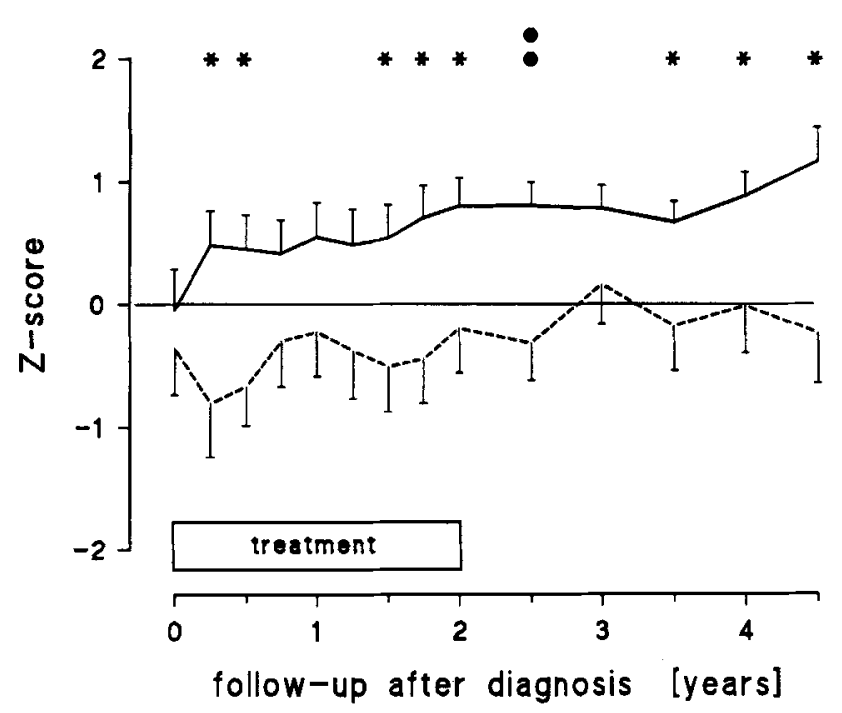

Fig. 1. Mean Z-scores ( \pm SEM) of weight for height of patients treated for ALL according to protocol 6 of the Dutch Leukemia Working Group. The patients receiving Dexa (solid line), $n=19$, are compared with the patients receiving Pred (broken line), $\mathrm{n}=11 .{ }^{*} P<0.05$, ${ }^{* *} P<0.005$, indicating the $\mathrm{t}$-test significance level.

weight for height of group Ia was $-0.1 \pm 1.3( \pm \mathrm{SD})$ and of group $\mathrm{Ib}-0.4 \pm 1.1$. This difference is not significant. Three months after start of therapy, the Z-score was $0.5 \pm 1.1$ for group Ia and $-0.8 \pm 1.4$ for group $\mathrm{Ib}$. The difference is significant $(P=0.01)$. In order to investigate whether the baseline difference in Z-scores of +0.3 in the two groups influenced the significance at 3 months, and to examine whether the difference at 3 months could be an artifact due to the five and three patients that were added to each group, respectively, we calculated the change from the baseline: $Z\left(Z=Z_{x}-Z_{0}, Z_{x}\right.$ is the $Z$ score at 3 months and $Z_{0}$ is the $Z$-score at diagnosis) of the 14 and 8 patients at 3 months. The $Z$ of the 14 patients treated with Dexa was $0.5 \pm 0.8$ and of the 8 patients treated with Pred was $-0.2 \pm 0.8$. This difference is also significant $(P=0.04)$. A significant difference between the two groups persisted during the whole follow-up period of 4.5 years.

As treatment with Dexa has a clear influence on weight

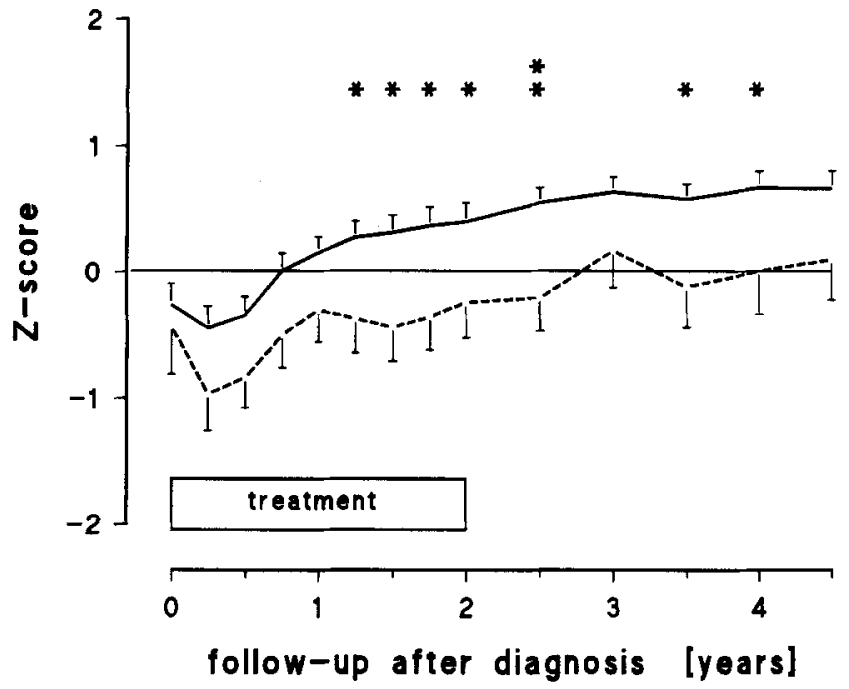

Fig. 2. Mean Z-score ( \pm SEM) of weight for height of patients treated for ALL with prophylactic CI (solid line), $n=54$, or without prophylactic $\mathrm{CI}$ (broken line), $\mathrm{n}=19$. All patients received Pred as corticosteroid. ${ }^{*} P<0.05,{ }^{*} P<0.01$, indicating the ANOVA significance level.

for height, 19 patients treated with Dexa, all from protocol 6 , were excluded from further analysis.

By means of two-way ANOVA, the influence of sex and $\mathrm{CI}$ on weight for height was studied. The Z-scores of weight for height of the irradiated group compared with the $\mathrm{Z}$-scores of patients who did not receive $\mathrm{CI}$ are shown in Figure 2. No significant differences between the groups were shown during the first year of therapy. At 2 and 4 years from diagnosis, the Z-scores were, respectively, $-0.2 \pm 1.1$ and $0.0 \pm 1.2$ for the non-CI group and $0.4 \pm 1.1$ and $0.7 \pm 0.9$ for the patients who received $\mathrm{Cl}$. These differences are significant, $P$ values, respectively, 0.04 and 0.05 .

Figure 3 shows the Z-scores of weight for height of the irradiated patients during the follow-up period of 12 years. At the end of treatment, 2 years after diagnosis, the $\mathrm{Z}$-score was $0.4 \pm 1.1$. Two years after cessation of therapy, the Z-scores were more positive: $0.7 \pm 0.9$. The Z-score remained above the mean of the normal 


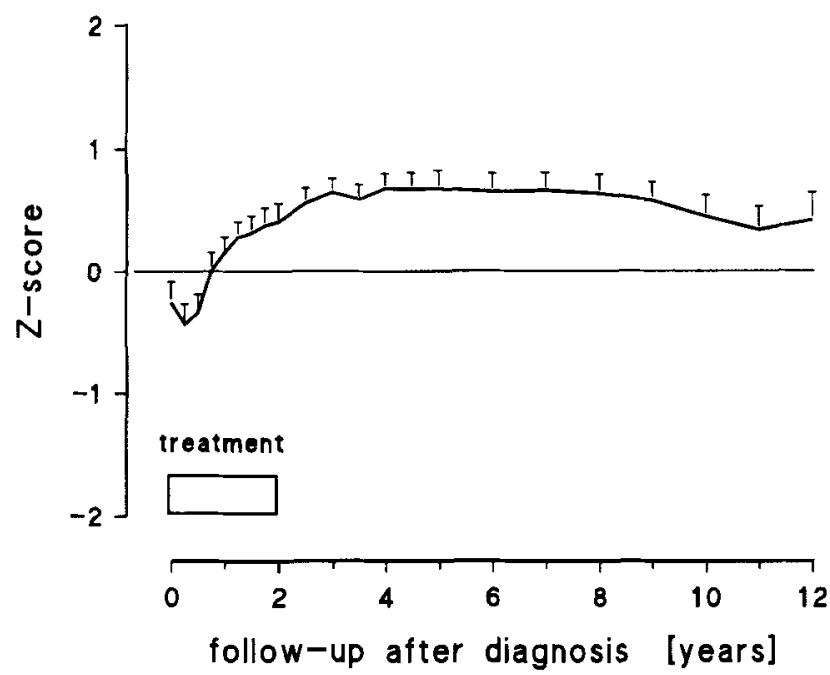

Fig. 3. Mean Z-scores ( \pm SEM) of weight for height of the irradiated patients with follow-up of 12 years.

population during the whole period of follow-up. The Z-score 12 years after diagnosis was $0.4 \pm 1.0$.

No differences in body weight development were noticed between boys and girls and between patients treated according to a normal-risk protocol vs. patients treated according to a more intensive high-risk protocol.

\section{DISCUSSION}

At diagnosis, the weight for height of patients in this study was not significantly different from the weight for height of the normal population. All patient groups, with the exception of the group of patients treated with Dexa, showed loss of weight during the first 3 months of treatment. The underweight of these patients during this phase of therapy could have attributed to the impairment of height growth, which was also demonstrated in our patients [17]. During the next 3-6 months, weight for height of the patients increased to normal, however, weight for height of the irradiated patients further increased during the second year of treatment and the first year after cessation of therapy. After this period, the weight for height of these patients stabilized but the Z-score remained above the mean of the normal population during the whole follow-up.

All studies [8-13,18] but one [19], with respect to weight, reported an increased weight velocity during or after treatment for ALL. Different factors as lack of physical exercise and poor dietary habits $[9,13]$ have been suggested to contribute to the excess weight gain in these patients who have suffered a serious illness. In this study, however, there is clear evidence that two treatment modalities, i.e., CI and treatment with Dexa, are associated with excessive weight gain. Patients treated without $\mathrm{CI}$ and patients who received Pred instead of Dexa showed normal weight development during the second year of therapy and after finishing treatment. Another study [13] has also identified $\mathrm{CI}$ as a risk factor for developing obesity. $\mathrm{CI}$ is also associated with impaired height growth $[13,18]$. Some authors $[13,18]$ suggested that compromised height is a major contributor of obesity and occurs when height compromise is not accompanied by parallel weight compromise. However, in the study of Schell et al. [18], patients receiving craniospinal irradiation were shown to be at increased risk for abnormally short stature but not for obesity. This finding suggests that other factors than just compromised height are responsible for obesity.

It is well known that especially endocrine disorders causing blunted growth are attended with overweight such as hypothyroidism, hypercortisolism, and growth hormone deficiency. Hypothalamic-pituitary dysfunction involving corticotropin and thyroid-stimulating hormone has not been demonstrated in children treated for ALL $[20,21]$. The impaired linear growth seen in children after $\mathrm{CI}$ has been thought to be attributed to minor abnormalities in the secretion of growth hormone [22,23]. DacouVoutetakis et al. [22] showed transient alterations in growth hormone secretion early after $\mathrm{CI}$ in children treated for ALL. A quantitative reduction in growth hormone secretion during puberty of children treated for ALL has been shown by Crowne et al. [23], suggesting that $\mathrm{CI}$ causes damage to the hypothalamic-pituitary axis affecting the secretion of growth hormone. The hypothalamus seems more vulnerable to radiation damage than the anterior pituitary [24]. Hypothalamic damage per se may cause obesity, however, the reported cases of hypothalamic obesity in children with ALL have always been demonstrated in patients with leukemic infiltration of the brain [14]. Studies on growth hormone profiles of children after low-dose CI [23] or total body irradiation [25] show a disturbance of frequency modulation of growth hormone secretion. Both studies $[23,25]$ postulate that disturbance of somatostatin secretion is the underlying mechanism for this observation. Our hypothesis is that neurosecretory dysfunction is responsible for the excessive weight gain in patients who received CI.

Excess of weight gain during and after treatment for ALL is also shown in children treated with Dexa, whereas children treated with Pred in an equivalent dose showed normal weight development. Besides the well-known peripheral effects of corticosteroids on growth and weight [26], glucocorticoids also exert an effect on the regulation of growth hormone secretion [27]. High-dose Pred (40 $\mathrm{mg} / \mathrm{m}^{2} /$ day) used in the treatment for ALL resulted in decreased growth hormone secretion during deep sleep as well as in response to arginine, insulin, and growth hormone releasing hormone administration [28]. Dexa, in a dose of $10 \mathrm{mg} / \mathrm{m}^{2} /$ day, completely suppressed the spontaneous growth hormone secretion in patients treated 
for ALL [29]. The inhibiting action of corticosteroids on growth hormone responses seems to be mediated by an enhancement of the somatostatin effect at the pituitary level [27].

Increase of weight in patients treated with Dexa is immediately shown after start of treatment, while all other patients show loss of weight during this phase of intensive chemotherapy. The loss of weight of most patients during the first months of therapy is presumably due to the side effects of cytotoxic drugs such as nausea and vomiting resulting in inadequate nutrition. Dexa, and not Pred, appears to circumvent this action and leads immediately after the start of treatment to excessive weight gain. It could be speculated that excessive weight gain after treatment with Dexa is also a consequence of neurosecretory dysfunction and that Dexa exerts a stronger central effect than Pred.

In patients who had undergone $\mathrm{CI}$, the overweight persisted during the whole follow-up period of 12 years. In view of the age distribution of the patients included in the study, we may conclude that, compared to age and height matched controls, the overweight of these patients persisted during puberty and adolescence. It is not yet clear if overweight in the Dexa-treated patients also persists during such a long period of time.

Dexa has proven in in vitro studies to have a stronger antileukemic effect than Pred [30]. So, in the future, Dexa could become a more common drug in the treatment of ALL. As obesity has serious long-term psychological and medical consequences, awareness of this potential complication could contribute to its prevention.

\section{ACKNOWLEDGMENTS}

We thank Mrs. B.C. de Jong for assistance in collecting the data.

\section{REFERENCES}

1. Berry DH, Elders MJ, Crist Wm, Land V, Lui V, Sexauer AC, Dickinson L: Growth in children with acute lymphoblastic leukemia: A pediatric oncology group study. Med Pediatr Oncol 11:39$45,1983$.

2. Robinson LL, Nesbit Jr ME, Sather HN, Meadows AT, Ortega JA, Hammond GD: Height of children successfully treated for acute lymphoblastic leukemia: A report from the late effects study committee of children cancer study group. Med Pediatr Oncol 13:14$21,1985$.

3. Kirk JA, Stevens MM, Menser MA, Tink A, Raghupathy P, Cowell $\mathrm{CT}$, Bergin $\mathrm{M}$, Vines RH: Growth failure and growth-hormone deficiency after treatment for acute lymphoblastic leukaemia. Lancet 1:190-193, 1987.

4. Clayton PE, Shalet SM, Morris-Jones PH, Price DA: Growth in children treated for acute lymphoblastic leukemia. Lancet 1:460 $462,1988$.

5. Moëll C, Garwicz S, Marky J, Mellander L, Karlberg J: Growth in children treated for acute lymphoblastic leukemia with and without prophylactic cranial irradiation. Acta Paediatr 77:688$692,1988$.

6. Katz JA, Chambers B, Everhart C, Marks JF, Buchanan GR: Linear growth in children with acute lymphoblastic leukemia treated without cranial irradiation. Clin Lab Observ 118:575-578, 1991.

7. Schriock EA, Schell MJ, Carter M, Hustu O, Ochs JJ: Abnormal growth patterns and adult short stature in 115 long-term survivors of childhood leukemia. J Clin Oncol 9:400-405, 1991.

8. Starceski PJ, Lee PA, Blatt J, Finegold D, Brown D: Comparable effects of 1800- and 2400-rad (18- and 24-Gy) cranial irradiation on height and weight in children treated for acute lymphocytic leukemia. Am J Dis Child 141:550-552, 1987.

9. Sainsbury CPQ, Newcombe RG, Hughes IA: Weight gain and height velocity during prolonged first remission from acute lymphoblastic leukaemia. Arch Dis Child 60:832-836, 1985.

10. Berglund G, Karlberg J, Marky I, Mellander L: A longitudinal study of growth in children with acute lymphoblastic leukemia. Acta Paediatr 74:530-533, 1985

11. Moëll C, Garwicz S, Westgren U, Aronson S, Wiebe T, Landberg T: Height, weight and growth hormone secretion in children treated for acute leukemia. Pediatr Hematol Oncol 1:167-172, 1984.

12. Tamminga RYJ, Kamps WA, Drayer NM, Humphrey GB: Longitudinal anthropometric study in children with acute lymphoblastic leukemia. Acta Paediatr 81:61-65, 1992.

13. Zee $\mathrm{P}$, Chen C-H: Prevalence of obsesity in children after therapy for acute lymphoblastic leukemia. Am J Pediatr Hematol Oncol 8:294-299, 1986.

14. Barak Y, Liban E: Hypothalamic hyperphagia, obesity and disturbed behaviour in acute leukemia. Acta Paediatr 57:153-156, 1968.

15. Roede MJ, van Wieringen JC:Growth diagrams 1980, Netherlands third nation-wide survey. Tijdsch Soc Gezondheidszorg 63(suppl 1985):1-34, 1985

16. van't Hof MA, Wit JM, Roede MJ: A method to construct age references for skewed skinfold data, using Box-Cox transformations to normality. Hum Biol 57:131-139, 1985.

17. Groot-Loonen JJ, Otten BJ, van 't Hof MA, Lippens RJJ, Stoelinga GBA: Influence of treatment modalities on prepubertal growth in children with acute lymphoblastic leukaemia. Pediatr Hematol Oncol 12:343-353, 1995.

18. Schell MJ, Ochs JJ, Schriock EA, Carter M: A method of predicting adult height and obesity in long-term survivors of childhood acute lymphoblastic leukemia. J Clin Oncol 10:128-133, 1992.

19. Wells RJ, Foster MB, d'Ercole AJ, McMillan CW: The impact of cranial irradiation on the growth of children with acute lymphoblastic leukemia. Arch Dis Child 137:37-39, 1983.

20. Swift PGE, Kearney PJ, Dalton RG, Bullimore JA, Mott MG, Savage DCL: Growth and hormonal status of children treated for acute lymphoblastic leukemia. Arch Dis Child 53:890-894, 1978.

21. Oliff A, Bode U, Beren BB, DiChiro G, Graves V, Poplack DG: Hypothalamic-pituitary dysfunction following DNS prophylaxis in acute lymphoblastic leukemia: Correlation with CT scan abnormalities. Med Pediatr Oncol 7:141-151, 1979.

22. Dacou-Voutetakis C, Xypolyta A, Haidas St, Constantinidis M, Papavasiliou C, Zannos-Mariolea L: Irradiation of the head. Immediate effects on growth hormone secretion in children. $J$ Clin Endocrinol Metab 44:791-794, 1977.

23. Crowne EC, Moore C, Wallace WHB, Ogilvy-Stuart AL, Addison GM, Morris-Jones PH, Shalet SM: A novel variant of growth hormone $(\mathrm{GH})$ insufficiency following low dose cranial irradiation. Clin Endocrinol 36:59-68, 1992.

24. Constine LS, Woolf PD, Cann D, Mick G, McCormick K, Raubertas RF, Rubin Ph: Hypothalamic-pituitary dysfunction after radiation for brain tumors. N Engl J Med 328:87-94, 1993.

25. Spoudeas HA, Davidson A, Ryalls MR, Powles RL, Treleaven 
JG, Meller ST, Brock CGD: Endocrine dysfunction after TBI and BMT in leukaemic children. Abstract book EBMT 3908:115, 1993 (Abstract).

26. Allen DB, Goldberg BD: Stimulation of collagen synthesis and linear growth by growth hormone in glucocorticoid-treated children. Pediatrics 89:416-421, 1992.

27. Giustina A, Wehrenberg WB: The role of glucocorticoids in the regulation of growth hormone secretion. Trends Endocrinol Metab 3:306-311, 1992.

28. Bozzola M, Locatelli F, Gambarana D, Moretta A, Valtorta A,
Giorgiani G, Cisternino M, Severi F: Effect of corticoid therapy on growth hormone secretion. Horm Res 36:183-186, 1991.

29. Marky I, Mellander L, Lannering B, Albertson-Wikland K: A longitudinal study of growth and growth hormone secretion in children during treatment for acute lymphoblastic leukemia. Med Pediatr Oncol 19:258-264, 1991.

30. Kaspers GJL, Pieters R, van Zantwijk CH, de Waal FC, van Wering ER, Veerman AJP: Sensitivity of childhood acute lymphoblastic leukemia cells to prednisone and dexamethasone assessed by the MTT assay. Haematol Blood Transfus 34:327-331, 1992. 